\title{
Application of Botulinum Toxin in Patients with Secondary Otalgia Caused by Bruxism
}

\author{
Kemal Kef $(\mathbb{D}$ \\ Private Kesan Hospital, Department of \\ ENT, Edirne, Turkey
}

\begin{abstract}
Aim: The aim of this study was to determine the effectiveness of botulinum toxin administration in patients who consulted the otolaryngology clinic with secondary otalgia caused by bruxism.

Introduction: Botulinum toxin can be applied to the hypertrophic muscles in patients who suffer from facial asymmetry even though they do not experience pain. Injection intervals and the condition of the muscles should be monitored as botulinum toxin applications to the muscles may result in decreased muscle strength and chewing difficulties.

Methods: This prospective study was conducted with bruxism patients at Private Kesan Hospital otorhinolaryngology outpatient clinic between August 2019 and December 2019. The diagnosis was based on the anamnesis and physical examination of the patient. The Visual Analogue Scale was used to evaluate patients' pain levels throughout the treatment.

Results: A total of 37 patients, between 19 and 51 years old, 22 (59.46\%) females and 15 (40.54\%) males, who consulted to the otolaryngology clinic in Private Kesan Hospital between August 2019 and December 2019 with a diagnosis of otalgia caused by bruxism were included in the study. Nine patients $(24.3 \%)$ had facial asymmetry due to masseter muscle hypertrophy. The average age of the participants was $34.00 \pm 9.13$ years old. Two weeks after the application of botulinum toxin, patients' complaints subsided. In patients with facial asymmetry, it was observed that asymmetry decreased after the 2nd month and noticeably improved after the 4th month.

Discussion: Bruxism should be considered in the differential diagnosis of patients with ear pain. Botulinum toxin can be applied in patients who do not respond adequately to classical treatments such as medical treatments, chewing training, neck and facial muscle relaxation techniques, psychological support, and dental splint applications.
\end{abstract}

Keywords: botulinum toxin, bruxism, facial asymmetry, otalgia, pain

\section{Introduction}

Pain in the ear has an important place in visits made to the otolaryngology polyclinics. Ear pain can be directly related to the diseases of the ear or it may occur as a result of the pathologies of neighboring areas and tissues. Pathologies such as tongue root-laryngeal, nasopharyngeal tumors direct the patient to the physician with ear pain before or simultaneously with the local findings. Due to their close neighborhood, pathologies of the teeth, temporomandibular joint, and chewing muscles may present with ear pain. Temporomandibular joint traumas may also play a role in the formation of ear pain. ${ }^{1}$

Bruxism is a person's teeth grinding or clenching strongly by rubbing their teeth together. These are considered to be parafunctional habits. ${ }^{2-4}$ Bruxism occurs in $8-21 \%$ of
Correspondence: Kemal Kef Private Kesan Hospital, Department of ENT, Edirne, Turkey

Tel +90532 70I 7086

Email dr.kemalkef@gmail.com 
people. ${ }^{2}$ It is more common in females than in males. It can be seen in any age group. Incidence increases in urban life and developed societies. ${ }^{5,6}$ Bruxism can be seen during both day and night. ${ }^{7}$ As a result of bruxism, ear pain occurs due to the high pressure of both muscles and joints. In long-term bruxism cases, apart from ear pain, unilateral or bilateral hypertrophy occurs in the chewing muscles. Hypertrophies occurring in masseter muscles can cause the lower half of the face to widen and result in a cosmetically undesirable asymmetrical appearance. As a result of bruxism, flattening and sawing appearance occurs on the chewing surfaces of the teeth, especially the incisors. During chewing, fatigue and pain in the temporal and masseter muscles occur. Tinnitus may occur in the ear. In addition to ear pain, patients also experience headaches, especially in the temporal region. Overgrown masseter muscles can disrupt salivary flow by pressing the muscle towards the parotid canal. As a result, periodic swallowing can cause pain, inflammation, and dry mouth. ${ }^{5,6,8}$

Bruxism can occur as a result of psychological and neurological diseases, as well as jaw/teeth closing problems, temporomandibular joint problems, sleep apnea, and acid reflux. ${ }^{9,10}$ Bruxism can also be seen in healthy individuals. Although bruxism can be noticed by the patients during the day, the more common nocturnal bruxism is mostly noticed by their partners. Vertical dimensions are reduced because of severe and prolonged bruxism due to abrasion/attrition in the teeth. The patient's nose-chin tip is shortened. Wrinkles occur around the eyes and lips. Lips become pale and overall, the patient has an older appearance. Patients complain of enlargement and asymmetry in the lower part of their faces.

The diagnosis of bruxism can be made with a history and physical examination. Radiological examinations can be made if necessary. Diagnostic methods such as electromyography (EMG), electroencephalography (EEG) can also be used (Figures 1 and 2). ${ }^{11,12}$

Polysomnography is also used in the diagnosis of sleep bruxism however, due to the high costs and the need for a dedicated sleep laboratory, clinical and self-reported diagnosis are still the most common methods in the diagnosis of sleep bruxism. ${ }^{13}$

In the treatment of bruxism, it is important to relieve the patient's pain first. Nonsteroidal anti-inflammatory drugs (NSAIDs) and muscle relaxants are used for pain control. The use of dental splints at night reduces both wear on the teeth and the load on the joints. ${ }^{12,13}$ Various dental splint applications such as anterior bite plate, posterior bite plate, occlusal splints, anterior positioning

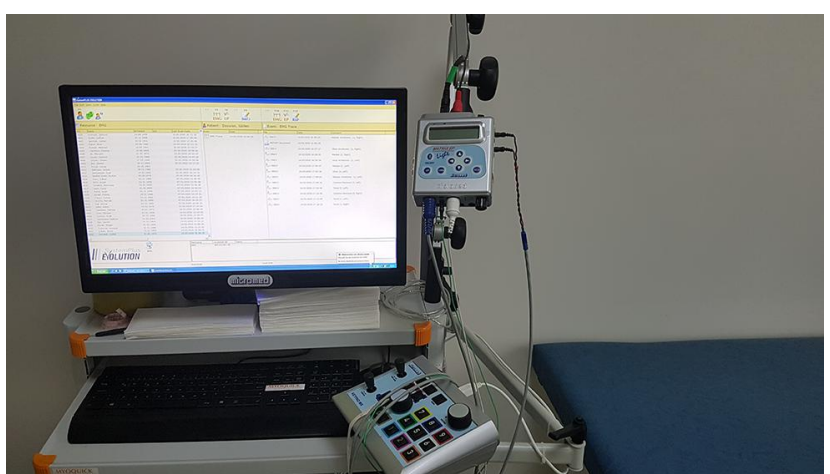

Figure I EMG device.

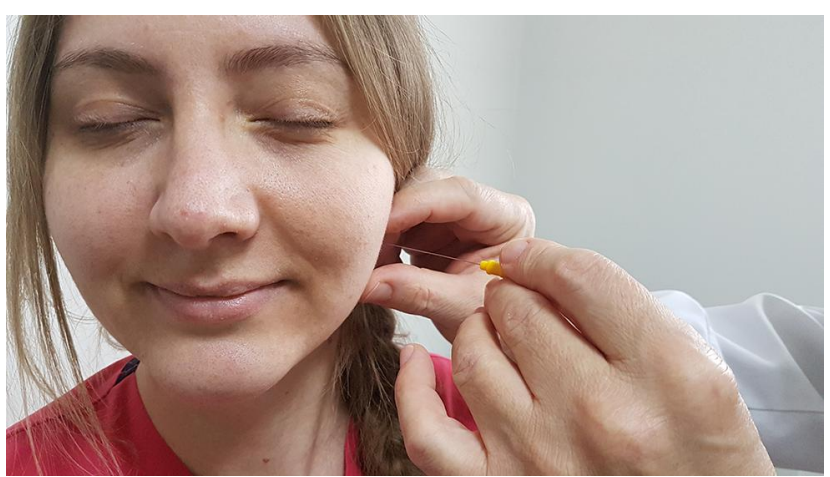

Figure 2 Left masseter case EMG application.

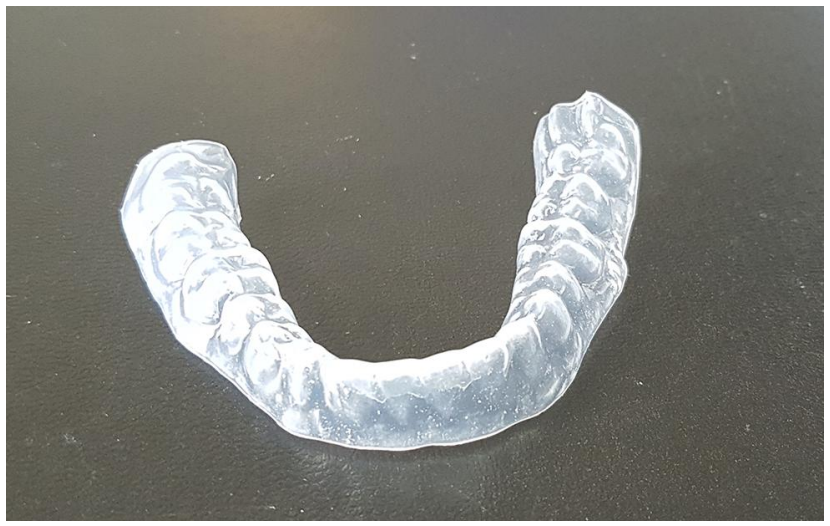

Figure 3 Dental splint.

splints, pivot splints, and soft-flexible splints can be made according to the desired purpose. Most often, stabilization splints (muscle relaxation splints, flat surface splints) and anterior reposition splints (ARS) are used. Dental splints can be applied to the upper or lower teeth (Figures 3-5). ${ }^{14,15}$ Patini et $\mathrm{al}^{16}$ stated the use of dental splints could also be useful in preventing the formation of facial wrinkles by improving occlusal conditions and reducing muscular activity. Physical therapy applications such 


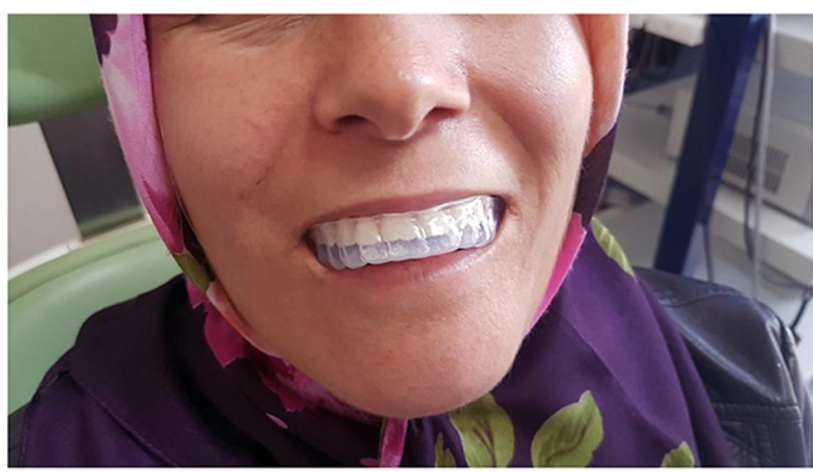

A

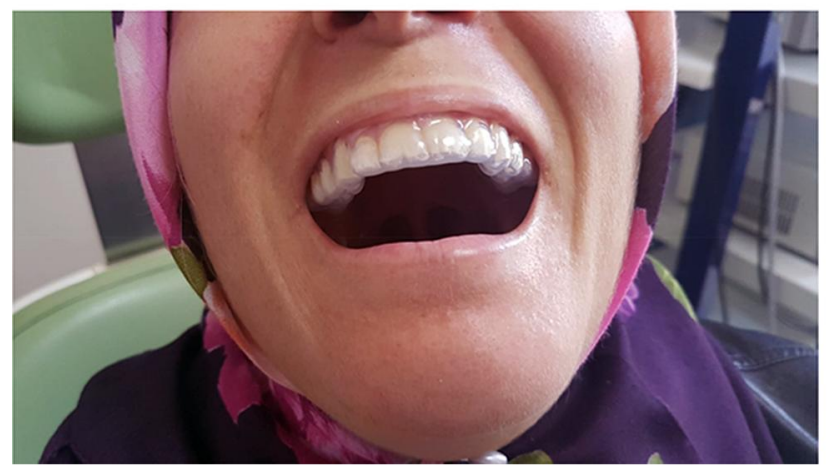

B

Figure 4 (A and B) Application of splints to the upper jaw.

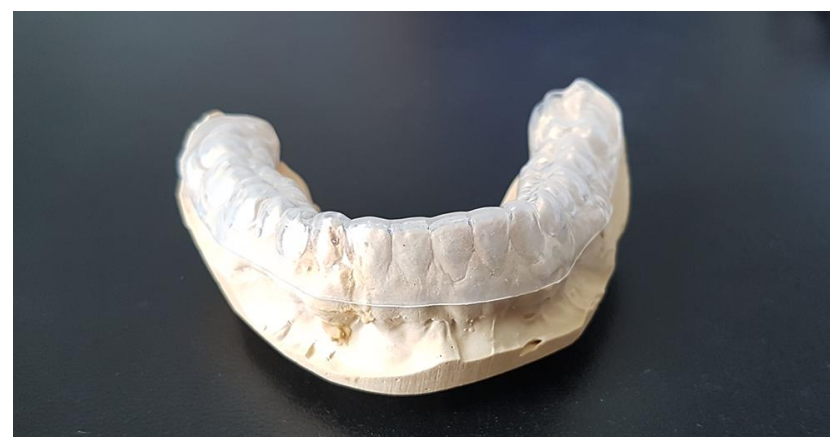

Figure 5 Application of splints to the lower jaw.

as superficial and deep tissue heaters, pain-blocking electric current for pain control can also be used in the treatment of bruxism. ${ }^{17}$ Psychotherapy and antidepressant drug treatments may be required in patients with anxiety and depressive features.

Botulinum toxin is applied to the chewing muscles in patients who experience chronic pain or in patients suffering from facial asymmetry despite the conventional treatments to prevent excessive contractions in the muscles. Thus, both the force applied to the joint and hypertrophy in the muscles are reduced. Botulinum toxin is four times more toxic than tetanus toxin and ten times more than curare. $^{18}$

Botulinum toxin affects the neuromuscular region, creating its therapeutic effect. It inhibits the release of acetylcholine and provides the formation of flux paralysis. It also acts by preventing contractions at the trigger points that cause the pain. Thus, it provides regression and improvement in muscular pain and unwanted hypertrophies for cosmetic reasons. ${ }^{18,19}$ Medications such as nonsteroidal anti-inflammatory drugs, aminoglycoside antibiotics, and aspirin should be avoided 6-7 days before the botulinum toxin application. Botulinum toxin applications are contraindicated in neuromuscular diseases such as myasthenia gravis. Botulinum toxin applications should not be performed during pregnancy and lactation as there are not enough evidence-based studies yet.

The dose of botulinum toxin to be made to the muscles is determined depending on the patient and the desired result. It is most commonly applied to the temporal and masseter muscles. Depending on the way patients use the chewing muscles, injections to the medial or lateral pterygoid muscles can also be performed. Application to pterygoid muscles is less common. If hypertrophy is bilateral, application to both sides of the face is made. In unilateral cases, botulinum toxin is applied only to the hypertrophic facial part. In cases where the muscles cannot be adequately identified by palpation, application of botulinum toxin can be accompanied by electromyography. ${ }^{11}$

The aim of this study was to determine the effectiveness of botulinum toxin administration in patients who consulted the otolaryngology clinic with secondary otalgia caused by bruxism.

\section{Materials and Methods}

This prospective study was conducted with bruxism patients at Private Kesan Hospital otorhinolaryngology outpatient clinic between August 2019 and December 2019. The inclusion criteria of these patients were to have their complaints for at least 3 months and to be resistant to other treatments for at least 6 weeks. The patients who had their complaints for less than 3 months, the patients who have not tried other treatment methods before, and the patients who did not attend to the follow-up appointments at the clinic regularly were excluded from the study. The diagnosis was based on the anamnesis (including the Helkimo index) and physical examination of the patient. The patients' facial symmetry was assessed by a grid picture method on an objective scale. Facial midline (midsagittal line) was established, and the left and right deviations were 
calculated. The asymmetry was also confirmed by subjective observation of the examiner.

Patients were asked to clench their teeth and their chewing muscles (temporal and masseter muscles) were palpated to determine which chewing muscles were used more. The borders of the muscles and the degree of hypertrophy, if any, were also investigated.

In preparation for the injections, the botulinum toxin vial was diluted with different amounts of saline according to the preference of the practitioner, the degree of bruxism, and muscle hypertrophy. If diluted with $2 \mathrm{cc}$ normal saline, 5 units of the toxin are obtained at $0.1 \mathrm{cc}$. If it is diluted with 4 cc normal saline, 2.5 units of the toxin are obtained at $0.1 \mathrm{cc}$. When the syringe is inserted into the vial, the normal saline must be drawn in with a vacuum. If this does not happen, it means that the vial content is defective and ineffective. The vials that do not meet these criteria are not used for treatment. Botulinum toxin vial retains its effect for 2 years without reconstitution (Figure 6). This period is 1 year for Dysport. For ease of application, 100 units of the vial was diluted with $4 \mathrm{cc}$ of saline. While preparing the botulinum toxin solution, the bottle should be turned very slowly as if it is rolled inside the hand. When it is shaken very hard and vigorously, the

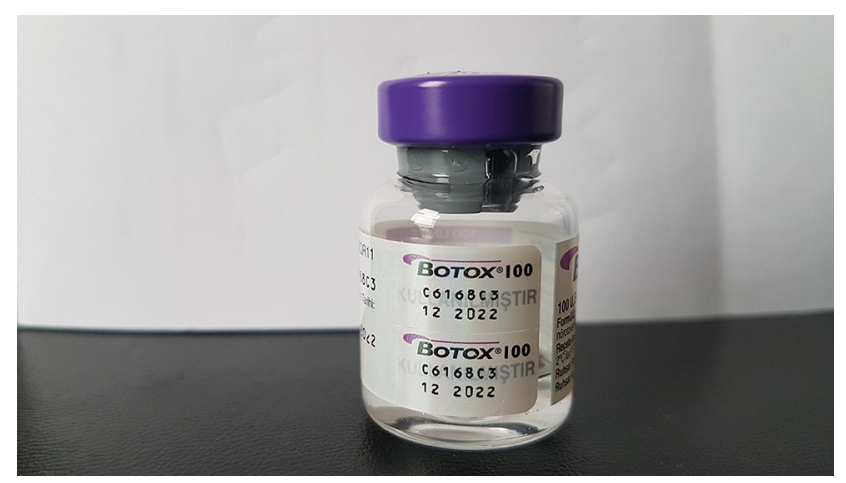

Figure 6 Botulinum toxin vial.

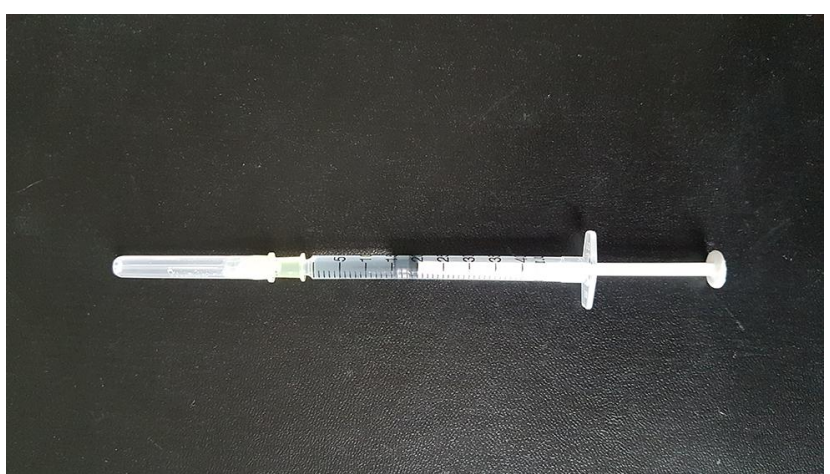

Figure 7 I cc injector used in botulinum toxin application.

natural structure of the toxin deteriorates and its effectiveness decreases. The prepared botulinum toxin is drawn into $1 \mathrm{cc}$ injectors and made ready for application (Figure 7).

The patients were asked to fill out the Visual Analogue Scale (VAS) forms to evaluate the pain levels before the application and at each control visits to the clinic at 2 weeks, 1 month, 2 months, 4 months, and 6 months after the injection (Figure 8).

If the patients felt a loss of effect or if they had any other complaints, they visited the clinic in between the scheduled control visits.

Botulinum toxin was applied to the temporal muscle region in 4-5 points and to the masseter muscle in 3-4 points. 5 units were applied to the thicker and hypertrophic muscles. Applications of 2.5 units were made to relatively thinner muscles. Since masseter muscle is mostly hypertrophic, generally 5 units of botulinum toxin was applied to 4 points of the masseter muscle. Before injection, the application area and injection points should be determined carefully (Figure 9).

Careful attention should be given to facial nerve branching, especially in the masseter muscle region, and injection into the facial nerve should be avoided. Masseter

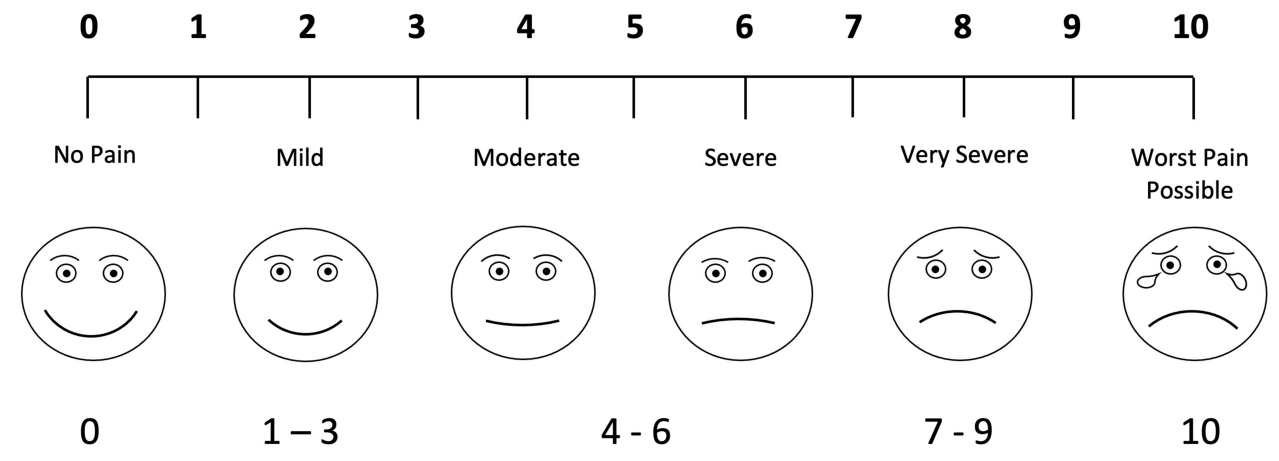

Figure 8 Visual Analogue Scale (VAS). 


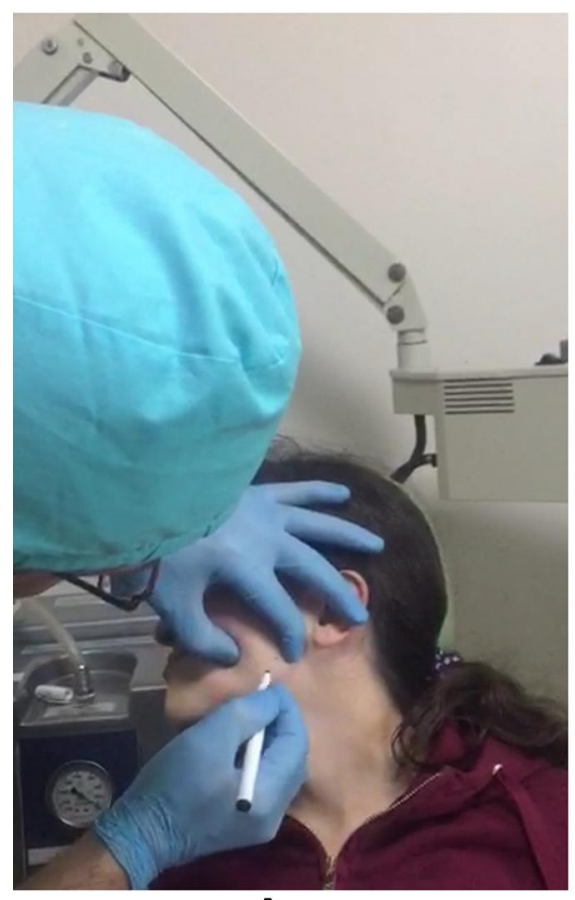

A

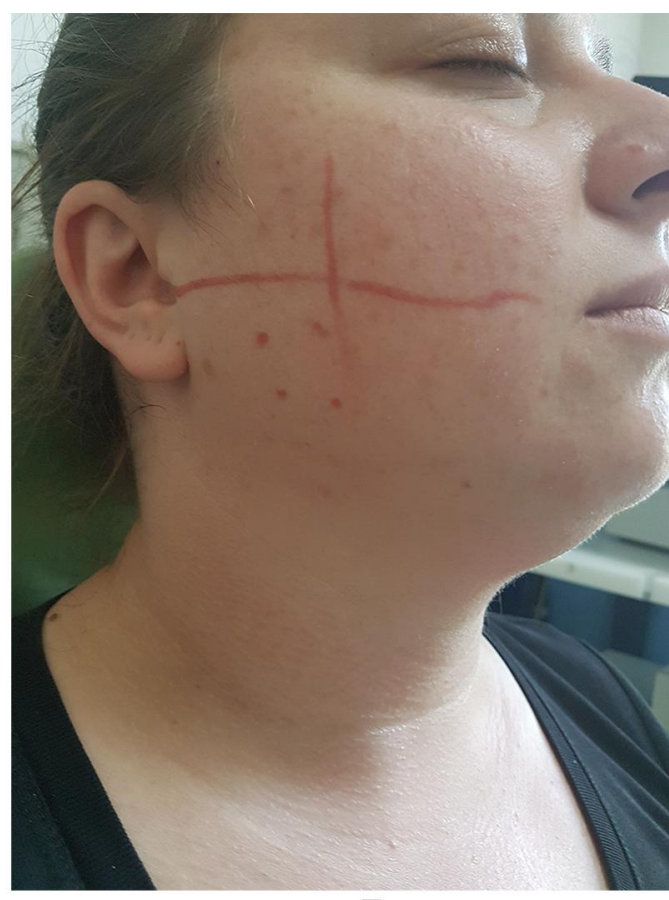

B

Figure 9 A-Determination of injection site in masseter muscle. B-Marked injection points.

case injection application points; Masseter was performed intramuscularly, under the line drawn from the auricular lobule to the corner of the mouth and behind the line drawn perpendicular to this line from the anterior muscle border. Attention was paid to this in applications as an asymmetrical appearance would occur on applications made over this line or very forward (Figure 10).

Before the applications to be made in the temporal muscle, the patients are told to squeeze their teeth and the temporal muscle borders are determined (Figure 11). A total of 20-40 units of botulinum toxin (an average of 25 units) are injected. A line is drawn from the lateral part of the eyebrow to the upper end of the auricle and $1.5-2 \mathrm{~cm}$ above this line a perpendicular line is drawn depending on the muscle volume and hypertrophy remaining in the anterior part of the line drawn from the ear in front of the ear.

If muscle hypertrophy is not very prominent, the dose should be low (20 units). Too much botulinum toxin can cause undesirable cosmetic appearance due to excessive volume loss in the temporal region and temporal collapse. If the application dosage and frequency are determined carefully according to the amount of hypertrophy in the muscle, the poor cosmetic result is also prevented. ${ }^{18-21}$
Statistical analysis was performed with the Statistical Package for the Social Science Program (version 22.0, SPSS Inc., Chicago, USA). Shapiro-Wilk test was performed as the test of normality. Post hoc Friedman tests were used for abnormally distributed variables. A value of $p<0.05$ was considered statistically significant. The procedures followed were in accordance with the ethical standards of the responsible committee on human experimentation and with the Helsinki Declaration of 1975. Written informed consent was obtained from all the study participants. Explicit written consent of the patients were obtained regarding the patients in the photographs.

\section{Results}

A total of 37 patients were included in this study. 22 $(59.46 \%)$ were female and $15(40.54 \%)$ were male. Nine patients $(24.3 \%)$ had facial asymmetry due to masseter muscle hypertrophy. The average age of the participants was $34.00 \pm 9.132$ years. The development of facial asymmetry due to masseter hypertrophy was present in $7(31.81 \%)$ of 22 female patients; It was seen in $2(13.3 \%)$ of 15 male patients. While 4 $(18.18 \%)$ of the female patients had unilateral masseter hypertrophy, $3(13.63 \%)$ had bilateral hypertrophy. 


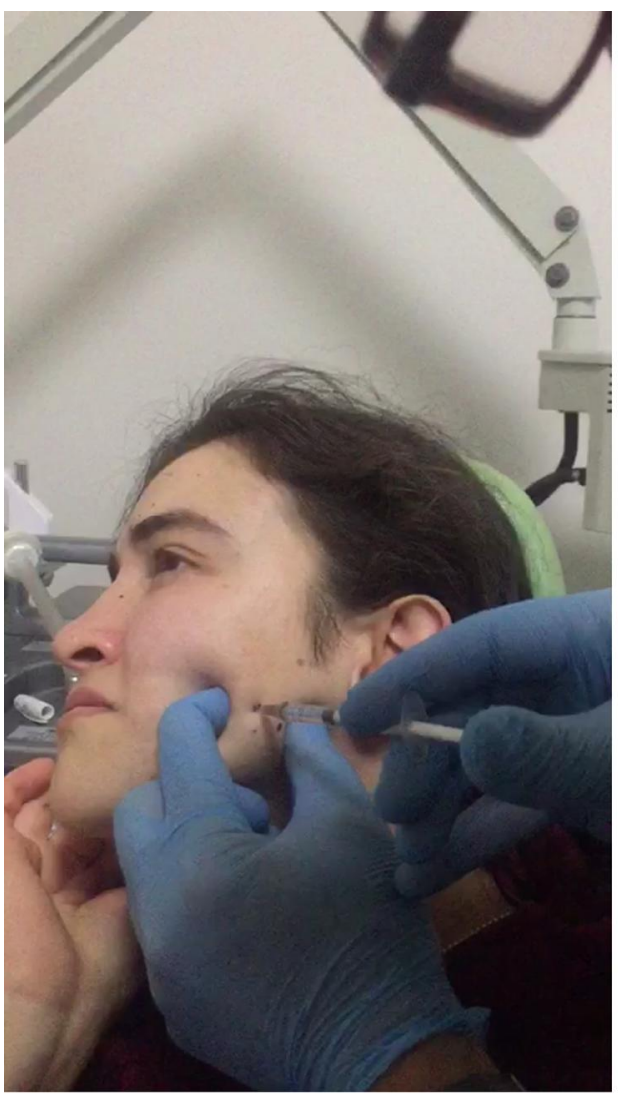

A

Figure 10 (A and $\mathbf{B})$ Botulinum toxin application to detected points.

Bilateral hypertrophy was present in $2(13.3 \%)$ of the male patients. 4 points were determined for each of the masseter and temporal muscles in male patients and 5 units of botulinum toxin was applied to each point. While female patients had hypertrophy in the masseter muscle, there was no hypertrophy in the temporal muscles.

Botulinum toxin was administered to 3 or 4 points in the hypertrophic masseter muscle in female patients as 2.5-5 units. There were no complaints related to the application during and after toxin application. Pain complaints decreased in patients two weeks after the botulinum toxin application (Table 1). In patients with facial asymmetry, it was observed that asymmetry decreased after the 2nd month and noticeably improved after the 4th month. As a result of botulinum toxin applications, no unwanted functional or cosmetic results were present in any patient. There was no significant difference in the VAS scores between female and male patients $(\mathrm{p}=0.190)$.

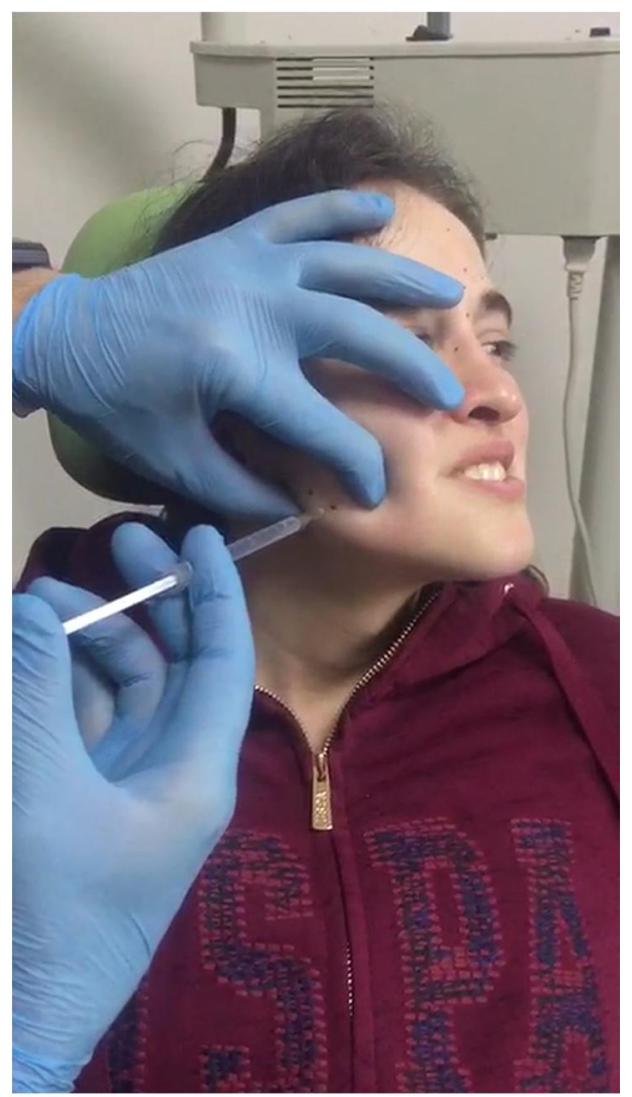

B

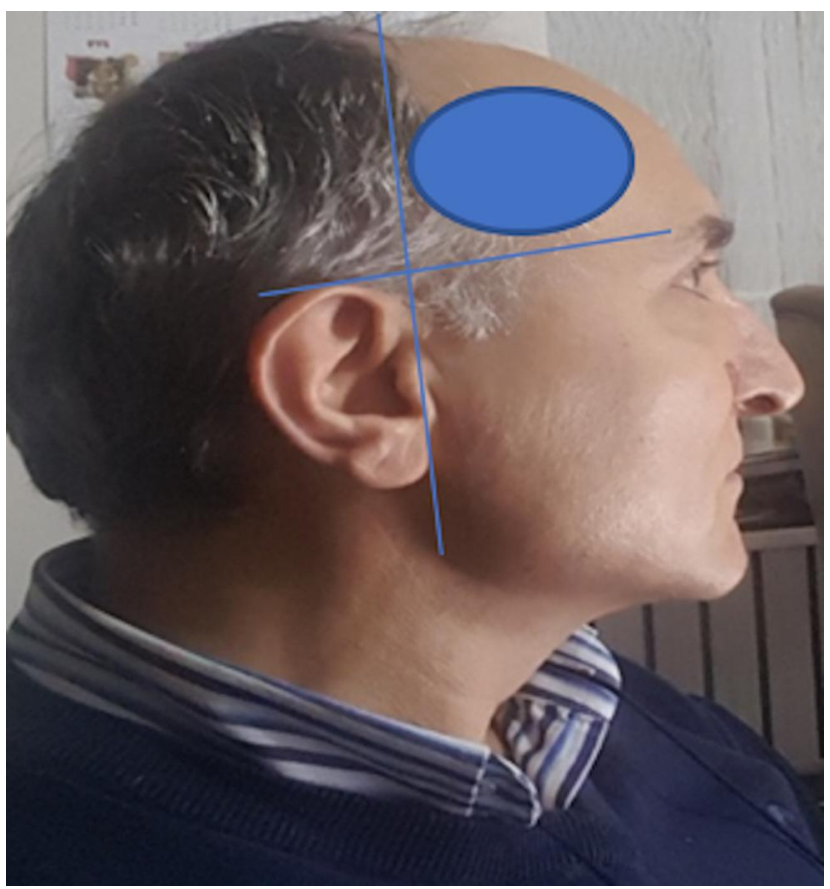

Figure I I The area where botulinum toxin can be applied in the temporal muscle. 


\section{Discussion}

Many patients visit the otolaryngology outpatient clinic with ear pain. Secondary causes should be considered in patients with normal otoscopic and microscopic ear examinations. Besides the causes of ear pain, there may also be pain that develops due to neighboring tissues and organs. Therefore, bruxism should also be considered in patients with ear pain, among secondary causes. The cause of bruxism has not been established yet. It is generally accepted that it was formed due to multi-factorial reasons. It can occur due to anxiety, emotional stress, hyperactive personality, sleep disorders, head and neck traumas, sleep apnea, teeth closing disorders (malocclusion), headache and ear pain, drug side effects. ${ }^{21}$

In some patients with bruxism, classical treatments such as medical treatments, chewing training, relaxation techniques of the neck and facial muscles, psychological support, psychotropic medication, physical therapy, or dental splint treatments may not produce the desired result. In these patients, the botulinum toxin application can be considered as a treatment option.

This study reveals that applying botulinum toxin to chewing muscles reduces both otalgia and muscle aches. Although it is rare, botulinum toxin may spread towards the major zygomatic muscle and risorius muscle during the application. In these cases, patients may experience undesirable cosmetic appearances such as asymmetric laughter and asymmetric facial appearance. If botulinum toxin injections are made carefully at appropriate points, such complications are not observed. This practice is accepted as the first botulinum toxin application to bruxism in the literature. Since they have somatic, psychological, and neurological origins, treatment of myofascial pain is challenging. $^{10,13,15}$

Botulinum toxin can be applied to the hypertrophic muscle or muscles in patients who suffer from facial asymmetry even though their pain decreases and want to recover. Injection intervals and the condition of the muscles should be monitored, as botulinum toxin applications may cause an excessive reduction in muscle strength and chewing difficulties. Therefore, botulinum toxin application doses should be carefully adjusted according to each patient and the condition of the patient's hypertrophic muscle or muscles. In this study, patients were called for control for 2 weeks following the application of botulinum toxin and it was checked whether the effect of the application started. At the end of the week, patients' pain was observed to decrease in accordance with the literature. ${ }^{21}$ Patients were called for control at the 1st, 2nd, 4th, and 6th months and their pain levels were evaluated by using VAS scoring and via physical examination. When compared with the preop VAS scores there was a significant decrease after the botulinum toxin application in all the VAS scores $(p<0.001)$ except preop scores compared to sixth-month scores $(\mathrm{p}=0.113)$. Considering that the loss of effect has occurred in 99.30 days \pm 11.32 days on average the VAS scores returning to preop levels is normal (Tables 1 and 2).

Table I Descriptive Statistics

\begin{tabular}{|c|c|c|c|c|c|c|}
\hline & $\mathbf{N}$ & Range & Minimum & Maximum & Mean & Std. Deviation \\
\hline Age & 37 & 32 & 19 & 51 & 34.00 & 9.132 \\
\hline Preop* & 37 & 4 & 5 & 9 & 6.65 & 1.338 \\
\hline Second_week* & 37 & 4 & 2 & 6 & 4.43 & 1.119 \\
\hline First_month* & 37 & 4 & 1 & 5 & 2.97 & 1.013 \\
\hline Second_month* & 37 & 3 & 0 & 3 & 1.46 & $\mathrm{I} .043$ \\
\hline Fourth_month* & 37 & 5 & 1 & 6 & 3.86 & 1.134 \\
\hline Sixth_month* & 37 & 4 & 3 & 7 & 5.16 & 1.143 \\
\hline Onset e.** & 37 & 10 & 6 & 16 & 11.43 & 3.078 \\
\hline Lose e.** & 37 & 44 & 75 & 119 & 99.30 & 11.323 \\
\hline Valid N (listwise) & 37 & & & & & \\
\hline
\end{tabular}

Notes: *VAS scores of the patient at each scheduled visit. **The time it took for the onset of effect and lose of effect in days. 
Table 2 Post Hoc Test Comparing Combinations of VAS Scores

\begin{tabular}{|l|l|l|}
\hline & Test Statistic & Adj. Sig.* \\
\hline 2nd W v. Pre & 1.986 & $\mathbf{0 . 0 0 0}$ \\
\hline Ist M v. Pre & 3.757 & $\mathbf{0 . 0 0 0}$ \\
\hline 2nd M v. Pre & 4.865 & $\mathbf{0 . 0 0 0}$ \\
\hline 4th M v. Pre & 2.662 & $\mathbf{0 . 0 0 0}$ \\
\hline Ist M v. 2nd W & 1.770 & $\mathbf{0 . 0 0 1}$ \\
\hline 2nd M v. 2nd W & 2.878 & $\mathbf{0 . 0 0 0}$ \\
\hline 4th M v. 2nd W & 0.676 & 1.000 \\
\hline 2nd W v. 6th M & -0.824 & 0.871 \\
\hline 2nd M v. Ist M & 1.108 & 0.163 \\
\hline Ist M v. 4th M & -1.095 & 0.178 \\
\hline Ist M v. 6th M & -2.595 & $\mathbf{0 . 0 0 0}$ \\
\hline 2nd M v. 4th M & -2.203 & $\mathbf{0 . 0 0 0}$ \\
\hline 2nd M v. 6th M & -3.703 & $\mathbf{0 . 0 0 0}$ \\
\hline 4th M v. 6th M & -1.500 & $\mathbf{0 . 0 0 8}$ \\
\hline
\end{tabular}

Note: *Statistically significant results are bolded.

Abbreviations: W, week; Pre, pre-botox-application; M, month.

The fascial asymmetry began to decrease from the $2 \mathrm{nd}$ month in patients with muscle hypertrophy and asymmetry improved in the 4th month. Due to ear pain, many patients with bruxism come to the otorhinolaryngology outpatient clinic. Considering the scientifically significant $(p<0.05)$ improvement on VAS scores of the patients, the botulinum toxin application should be considered as a treatment method. It is an effective alternative in the treatment of chronic and persistent bruxism. As with other temporomandibular joint diseases, a multidisciplinary treatment approach is required in bruxism patients. If necessary, cooperation should be made with relevant branches such as dentists, oral and maxillofacial surgeons, orthodontists, psychiatrists, psychologists, and physical therapy specialists. The multidisciplinary approach will increase the success of the treatment.

Limitation: The limitations of this study are the small sample size and the absence of results of the following botulinum toxin applications.

\section{Conclusions}

Botulinum toxin application can be used as an effective treatment method in bruxism. It reduces the pain and hypertrophy in the chewing muscles. However, a need for an expert for application the expense of the botulinum toxin vials, and the need to repeat the application restricts the use. Nevertheless, it can be used as an effective option in cases where there is no response to conservative methods.

\section{Data Sharing Statement}

The statistical data used to support the findings of this study are available online on: https://drive.google.com/ file/d/1c34zKxyLjigoeK6UkNxHqpAzV37qGPVg/view? usp=sharing.

\section{Ethical Approval}

This study was approved by the Scientific Research Ethical Committee of Trakya University School of Medicine (Protocol Code: TÜTF-BAEK 2020/447). The procedures followed were in accordance with the ethical standards of the responsible committee on human experimentation and with the Helsinki Declaration of 1975.

\section{Consent}

Written informed consent was obtained from all the study participants. The explicit written consent of the participants whose photographs are used in the paper was obtained.

\section{Acknowledgments}

Special thanks are due to Nur Gülce İşkan for her support in the VAS graphic design and the statistical analysis.

\section{Funding}

No funding was received for this study. The expenses were met by the author.

\section{Disclosure}

The author declared no potential conflicts of interest with respect to this work, the research, authorship, and/or publication of this article.

\section{References}

1. Plesh O, Adams SH, Gansky SA. Temporomandibular joint and muscle disorder-type pain and comorbid pains in a national US sample. J Orofac Pain. 2011;25(3):190-198.

2. Türken R, Büyük KS, Yaşa Y. Diş hekimliği fakültesi öğrencilerinde temporomandibular eklem rahatsızlıklarının ve ağı sağığı alışkanlıklarının değerlendirilmesi [Evaluation of temporomandibular joint discomfort and oral health habits in dentistry students]. Acibadem Üniversitesi Saglik Bilimleri Dergisi. 2020;11(2):208-213. doi:10.31067/0.2018.83 
3. Emodi-Perlman A, Eli I, Friedman-Rubin P, et al. Bruxism, oral parafunctions, anamnestic and clinical findings of temporomandibular disorders in children. J Oral Rehabil. 2021;39(2):126-135.

4. Fernandes G, Franco-Micheloni AL, Siqueira JTT, Gonçalves DAG, Camparis CM. Parafunctional habits are associated cumulatively to painful temporomandibular disorders in adolescents. Braz Oral Res. 2016;30(15):e15.

5. Reddy SV, Kumar MP, Sravanthi D, Mohsin AHB, Anuhya V. Bruxism: a literature review. J Int Oral Health. 2014;6(6):105-109.

6. Murali RV, Rangarajan P, Mounissamy A. Bruxism: conceptual discussion and review. J Pharm Bioallied Sci. 2015;7(Supp 1):265-270. doi:10.4103/0975-7406.155948

7. Wetselaar P, Vermaire E, Lobbezoo F, Schuller AA. The prevalence of awake bruxism and sleep bruxism in the dutch adult population. J Oral Rehabil. 2019;46(7):617-623. doi:10.1111/joor.12787

8. Canto GDL, Singh V, Bigal ME, Major PW, Flores-Mir C. Association between tension-type headache and migraine with sleep bruxism: a systematic review. $J$ Head Face Pain. 2014;54:1460-1469. doi:10.1111/head.12446

9. Kuc J, Szarejko KD, Sierpinska T. Evaluation of orofacial and general pain location in patients with temporomandibular joint disorder-myofascial pain with referral. Front Neurol. 2019;10:546. doi:10.3389/fneur.2019.00546

10. Manfredini D, Lobbezoo F. Role of psychosocial factors in the etiology of bruxism. J Oral Rehabil. 2009;23(2):153-166.

11. Christian L, Shoffel-Havakuk H, Johns MM. EMG guided botulinum toxin injection for adductor spasmodic dysphonia. CSurgeries. 2017. doi:10.17797/vefreq97o4

12. Kim JW, Park JH, Park KN, Lee SW. Treatment efficacy of electromyography versus fiberscopy-guided botulinum toxin injection in adductor spasmodic dysphonia patients: a prospective comparative study. Sci World J. 2014;327928. doi:10.1155/2014/327928
13. Chien YC, Seferovic D, Holland JN, Walji M, Adibi S. When should sleep bruxism be considered in the diagnosis of temporomandibular disorders? Oral Surg Oral Med Oral Pathol Oral Radiol. 2020;130 (6):645-650. doi:10.1016/j.oooo.2020.08.029

14. Jagger R. The effectiveness of occlusal splints for sleep bruxism. Nature. 2008;9(21):23. doi:10.1038/sj.ebd.6400569

15. Lobbezoo F, Brouwers JEIG, Cune MS, Naeije M. Dental implants in patients with bruxing habits. J Oral Rehabil. 2006;33(2):152-159. doi:10.1111/j.1365-2842.2006.01542.x

16. Patini R, Gallenzi P, Meuli S, Paoloni V, Cordaro M. Clear aligners' effects on aesthetics: evaluation of facial wrinkles. J Clin Exp Dent. 2018;10:e696-e701. doi:10.4317/jced.54925

17. Mesko ME, Hutton B, Skupien JA, et al. Therapies for bruxism: a systematic review and network meta-analysis (protocol). Syst Rev. 2017;6(4):1-6. doi:10.1186/s13643-016-0397-z

18. Kwon KH, Shin KS, Yeon SH, Kwon DG. Application of botulinum toxin in maxillofacial field: part I. Bruxism and square jaw. Maxillofac Plast Reconstr Surg. 2019;41(1):38. doi:10.1186/s40902019-0218-0

19. Albert M, Magar R, Findley L, et al. Retrospective evaluation of the dose of dysport and botox in the management of cervical dystonia and blepharospasm: the real dose study. Mov Disorders. 2005;20 (8):937-944. doi:10.1002/mds.20468

20. Atalay Y, Asutay H, Acar AH. The evaluation of the clinical effects of botulinum toxin on nocturnal bruxism. Pain Res Manage. 2017. doi: $10.1155 / 2017 / 6264146$

21. Sidebottom AJ, Patel AA, Janaki A. Botulinum injection for the management of myofascial pain in the masticatory muscles. A prospective outcome study. $\mathrm{Br} J$ Oral Maxillofacial Surg. 2013;51(3):199-205. doi:10.1016/j.bjoms.2012.07.002
Journal of Pain Research

\section{Publish your work in this journal}

The Journal of Pain Research is an international, peer reviewed, open access, online journal that welcomes laboratory and clinical findings in the fields of pain research and the prevention and management of pain. Original research, reviews, symposium reports, hypothesis formation and commentaries are all considered for publication. The manuscript management system is completely online and includes a very quick and fair peer-review system, which is all easy to use. Visit http:// www.dovepress.com/testimonials.php to read real quotes from published authors. 